\title{
Mobile Distribution for Personal Security
}

\author{
Gokul Krishna C.S $\mathbf{1}$, Jambunathan.S ${ }^{2}$ \\ Department of Information Technology, Sri Krishna Arts and Science College, Coimbatore, India ${ }^{1}$ \\ Department of Computer Science, Sri Krishna Arts and Science College, Coimbatore, India ${ }^{2}$
}

\begin{abstract}
This paper entitled "Mobile distribution for personal security" is an application that is used to store data about an individual like Body Mass Index (BMI), personal information and relative information which is secured by high level of authentication that consists of three levels. The user has to cross three levels of authentication levels in order to get access to the application. Even if one of authentication fails the user cannot enter. After successful login the user is taken to the dashboard where he/she can select and use any of the three modules BMI, Personal information and Relative information.
\end{abstract}

Keywords: Mobile distribution, Body Mass Index (BMI), Personal Information and Relative Information

\section{INTRODUCTION}

This paper "Mobile distribution for personal security" tells in detail about the application which is used to keep up records of a person's BMI calculation, personal details and relative details with high level of security authentication that consists of three levels. This application aims at creating a secure way of storing records of a particular individual. Through this application any number of users can make use of the modules to store data at the same time. It allows users to calculate BMI, store personal details and relative details of a particular person. For entering and moving forward, they have to enter authentication security pin. The authentication process provides the user to safeguard their private information. After the successful login, the users are directed to the dashboard where they can choose any one of the available modules. Users can also view the details that they have stored. The administrator is given special privileges to get access to the database. The relative information gives the details in the emergency situations. This application is done on domain C\# .Net using the software Microsoft Visual studio 2010 and SQL server management studio. This application is tested using unit testing and acceptance testing.

\section{SYSTEM SPECIFICATIONS}

A. Hardware Specifications

- Operating System: Windows 7

- Processor (with Speed): Intel(R) Core(TM) i5-2450M CPU $2.50 \mathrm{GHz}$

- Hard Disk Size: $400 \mathrm{~GB}$ and above

- RAM: 4GB

- Monitor: 15' CRT

- Keyboard: 101 Keys

- Mouse: TouchMate

B. Software Specifications

- Front End: Visual Studio 2010 Ultimate

- $\quad$ Back End: SQL Server 2008

- Editor: Windows Application

- Development Environment: C\# .Net

\section{SYSTEM STUDY}

This application is used to store records of a person's BMI calculation, personal information and relative information with high level of security authentication consisting of three levels.

\section{A. Existing System}

The mobile distribution activity is absent in the olden days. The relative information is stored in the sheets or any notes that gives the loss of information. It is very low in performance. The security is absent. There is loss of data in storing the all information. In case of emergency, information cannot be reached in proper time. 


\section{IJARCCE}

\section{International Journal of Advanced Research in Computer and Communication Engineering}

Vol. 8, Issue 1, January 2019

\section{B. Disadvantages of Existing System}

- $\quad$ There is a possibility of human errors at any stage of process.

- $\quad$ Those records maybe insecure.

- $\quad$ Previously, it was used in websites.

- $\quad$ Some important information may not be provided in existing systems.

- $\quad$ Storage of data is by CD or hard discs.

- There is no proper identification to view the records.

- Generating important reports like the tests conducted in a particular day is time consuming.

\section{Proposed System}

The new proposed system is developed by satisfying all the end user requirements. The proposed system has maximum efforts towards overcoming all the problems of existing system in a user friendly manner. The secure authentication gives the user protected environment.

D. Advantages of Proposed System

- $\quad$ This application contains user friendly interface.

- The dashboard explores the navigation to other modules.

- $\quad$ The users can analyze any details of the modules.

- $\quad$ Any new processes can be easily updated here.

- The automation is the important logic of the application.

- The main authorization is accessed by the main user.

- Unauthorized people cannot access the application.

- It is considered to be scalable, flexible, efficient and fast.

- It is more reliable than traditional method and has real time access.

\section{SYSTEM DESIGN}

Design is the primary step for any engineered product or system in development stage. It is the place where quality is fostered in software development. It provides us with representations of software that can assess for quality. It is the only way that we can accurately translate a customer's view into a finished software product or system.

\section{A. Module Description}

1. Welcome: starting page of the application.

2. About: displays a small information about the modules.

3. Port Id: level 1 authentication of the application. Only if the credentials match it takes to level 2 authentication processes.

4. Port Login: level 2 authentication of the application. Only if the details are matched correctly the authentication succeeds and proceeds forward.

5. User Login: level 3 authentication of the application. The user logins with user name and password. Only if the details are correct the authentication succeeds else fails.

6. Dashboard: the user interactive area where the user can select any one of the three modules namely BMI, Personal information and relative information.

7. BMI: used to calculate the Body Mass Index (BMI) of an individual.

8. Personal Information: used to store details like bank account number, pan card number, aadhar card number, etc. of an individual.

9. Save Grid: used to view the personal information of an individual in grid form.

10. Relative Information: used to store relative details of an individual.

11. Save Grid: used to view the relative information of an individual in grid form.

\section{B. Input Design}

The input designs are developed in such a way that validation can be easily understood. Menus and interactive dialogues are provided to make sure that the navigation between modules takes place in an easy and user-friendly manner. For better understanding of the user, it also displays the static and dynamic content.

\section{Output Design}

Output forms are designed specifically according to the user needs. Results are formatted to enhance clarity. It is designed in a way that all the required data of the user is present. 
Vol. 8, Issue 1, January 2019

\section{Table Design}

Database Design is a crucial factor in the performance of a system, both in terms of system timings and in the case with which the system can be maintained or modified. It is used to allow easy retrieval of data with response to queries and requests. It is used to shorten the safeguarding of data through updates, insertions and deletions and also to decrease the need to restructure or reorder the data when new requirements arise.

Table: 1 BMI table

\begin{tabular}{|c|c|c|c|}
\hline Column name & Data type & Size & Description \\
\hline bid & int & 3 & Primary key \\
\hline bname & varchar & 30 & Name of the person \\
\hline weightkg & varchar & 10 & Weight in $\mathrm{kg}$ \\
\hline heightm & varchar & 10 & Height in $\mathrm{m}$ \\
\hline bmi & varchar & 10 & Bmi \\
\hline
\end{tabular}

Table: 2 Personal Information table

\begin{tabular}{|c|c|c|c|}
\hline Column name & Data type & Size & Description \\
\hline pid & int & 3 & Primary key \\
\hline name & varchar & 30 & Name of the person \\
\hline dob & varchar & 20 & Date of birth \\
\hline age & int & 3 & Age of the person \\
\hline gender & varchar & 10 & Gender of the person \\
\hline bloodgroup & varchar & 10 & Bloodgroup of the person \\
\hline fathername & varchar & 30 & Father name of the person \\
\hline mothername & varchar & 30 & Mother name of the person \\
\hline paddress & varchar & 50 & Address of the person \\
\hline nationality & varchar & 10 & Nationality of the person \\
\hline martialstatus & varchar & 10 & Marital status of the person \\
\hline occupation & varchar & 20 & Occupation of the person \\
\hline aadharcardno & bigint & 20 & Aadhar no of the person \\
\hline pancardno & bigint & & Pan card no of the person \\
\hline bankaccountno & bigint & & Back account no of the person \\
\hline personalpic & image & & Photo of the person \\
\hline
\end{tabular}

Table: 3 Relative Information table

\begin{tabular}{|c|c|c|c|}
\hline Column name & Data type & Size & Description \\
\hline rid & int & 3 & Primary key \\
\hline name & varchar & 30 & Name of the person \\
\hline age & int & 3 & Age of the person \\
\hline relation & varchar & 10 & Relation name \\
\hline phoneno & bigint & & Phoneno of the person \\
\hline raddress & varchar & 50 & Address of the person \\
\hline favourites & varchar & 20 & Favourites of the person \\
\hline reltype & varchar & 10 & Closelfar \\
\hline relativepic & image & & Photo of the person \\
\hline
\end{tabular}

\section{TESTING}

Testing is a method of executing a program with the goal of discovering an error. A fine test case is one that has a chance of discovering an undiscovered error.

\section{A. Unit Testing}

Unit testing means finding errors in each and every module. It is in-general white box testing oriented. They can be conducted in parallel for several modules. Using technical design, errors are found and exposed for proper functioning of the modules.

\section{B. Acceptance Testing}

The admin want to access the three level authentication details are updated. The web application will run on all browsers/versions and also easily loaded. A form can contain port login and user login for enter to the activity. The 
Vol. 8, Issue 1, January 2019

form fields are validated for the information used inside the form. The form value must be stored in database in correct manner.

Table: 4 Testing Table

\begin{tabular}{|c|c|c|c|c|}
\hline S.no & Test Input & Expected Result & Actual Result & Test Result \\
\hline 1 & $\begin{array}{c}\text { Valid user name } \\
\text { and Password }\end{array}$ & Login to admin panel using port id & Login to main page & Success \\
\hline 2 & Invalid username & $\begin{array}{c}\text { Appropriate message is displayed } \\
\text { and the fields are cleared }\end{array}$ & $\begin{array}{c}\text { Invalid username } \\
\text { message is displayed }\end{array}$ & Success \\
\hline 3 & Invalid password & $\begin{array}{c}\text { Appropriate message is displayed } \\
\text { and the fields are cleared }\end{array}$ & $\begin{array}{c}\text { Invalid password } \\
\text { message is displayed }\end{array}$ & Success \\
\hline
\end{tabular}

\section{CONCLUSION}

In this paper, we provided all latest technologies, programming details for forms, designing, testing details for BMI, information sharing through the mail for relatives and report details for all BMI details can improve their flexibility in their own convenient time to save the information. The personal information module will be helpful in performing paperless work and managing the data. The relative information is needed in any emergency situations. It may be consisting of all relations or specific people alone. Everyone can use this application with ease and according to their needs. This could be the one to change data management in certain areas of work.

\section{SCOPE FOR FUTURE ASPECTS}

The proposed web application contains knowledge source for the all personal details. This paper has been specially customized and developed for personal laptop/desktop details to select the secured method. Through this paper any number of intruders cannot select their data at the same time. Through this application each personal detail can improve their technical problems. In future we can add more number of features, so that the paper becomes very user friendly. Some of the features that can be added are

- $\quad$ Sending the notifications for intruders enters the files through website

- $\quad$ Sending the reports details through SMS login information.

- $\quad$ Extra personal details are can be easily fetched through app by three level authentication.

- In future it is implemented with biometric authentication.

- In future, it can be view in android app with quick response.

\section{REFERENCES}

[1]. Steven Holzner,VB.NET programming Golgotia publication, 1997

[2]. Tim Anderson, VB.NET programming Dreamtech publication, $2^{\text {nd }}$ Edition 2005

[3]. Jesse liberty Orelilly publication, $2^{\text {nd }}$ Edition

[4]. .NET: Interview Questions" by Shivprasad Koirala, $3^{\text {rd }}$ edition

[5]. Visual Basic .NET Programming Black Book" by Steven Holzner

[6]. Programming with C\# .Net" by Sathiaseelan J G R, $4^{\text {th }}$ edition

[7]. www.vbdotnetheaven.com

[8]. www.w3school.com

[9]. www.wikipedia.com

[10]. www.quora.com

[11]. www.tutorialspoints.com 